\title{
EL PROBLEMA DE LA AUTORIDAD EN LA CULTURA (PROFECÍA, INTERPRETACIÓN, FICCIÓN)
}

\author{
THE PROBLEM OF AUTHORITY IN CULTURE (PROPHECY, \\ INTERPRETATION, FICTION)
}

\author{
Luis Galván \\ Universidad de Navarra
}

\begin{abstract}
This paper addresses the issue of the crisis or vanishing of authority in contemporary culture in the particular form of the problem of legitimacy in the use of language. What grounds can speakers find in order to justify their claim to be listened to? I point out that, since this problem has been examined for quite some time in the area of Biblical studies, we could improve our understanding of the current situation by means of an interdisciplinary dialogue. From this perspective, I consider claims to authority under three headings: prophecy, or the individual authority of the speaker; interpretation, or authority derived from a written source; fiction, or renouncing authority; and show that there is a degree of convergence in the direction of an anti-foundationalist stance.
\end{abstract}

KEYWORDS: Bible; Culture. Authority; Legitimacy; Prophecy; Interpretation; Fiction; Anti-foundationalism.

RESUMEN • Este ensayo trata de la crisis o pérdida de la autoridad en la cultura contemporánea, bajo el aspecto particular de los problemas de legitimidad para el uso del lenguaje. ¿Qué fundamentos pueden invocar los hablantes para justificar su pretensión de ser escuchados? Señalo que, habiendo sido este problema objeto de atención para los estudios bíblicos durante largo tiempo, un diálogo interdisciplinar puede mejorar nuestra comprensión de la difícil situación actual. Desde esta perspectiva, examino las pretensiones de autoridad bajo tres nociones: profecía, o la autoridad individual del hablante; interpretación, o la autoridad derivada de una fuente escrita; ficción, o la renuncia a la autoridad. Muestro que hay una cierta convergencia hacia un planteamiento antifundacionalista.*

PALABRAS CLAVES: Biblia; Cultura; Autoridad; Legitimidad; Profecía; Interpretación; Ficción; Antifundacionalismo.

\footnotetext{
* Versiones preliminares de este trabajo se han presentado en el curso de verano «La Biblia en la tradición cultural y la cultura contemporánea» (Pamplona, agosto de 2019) y en el XXXVI Simposio de Teología "La Biblia, lengua materna del mundo actual» (Universidad de Navarra, Pamplona, 16-18 de octubre de 2019). Agradezco a los organizadores y participantes en esos eventos su apoyo y sugerencias, así como a la revista Imago la posibilidad de publicar el texto. Una versión distinta, con otro enfoque y mayor elaboración de ciertos aspectos, se publicará en el volumen que recoge las contribuciones al simposio mencionado.
}

Fecha de recepción: 16-9-2019 / Fecha de aceptación: 9-10-2019 
El presentar una cuestión en términos de autoridad no es la mejor manera de hacerla amable, pero al menos proporciona un acceso relativamente concreto y claro a una problemática que es a la vez fundamental y multiforme. Hace poco más de cincuenta años, Michel Foucault abría la conferencia "¿Qué es un autor?» con la pregunta: “¿Qué importa quién habla?», para indicar que la cuestión del autor no es la cuestión última, sino que depende de otra: ¿qué consecuencias tiene para el proceso comunicativo que el autor sea uno o sea otro, que sea conocido o sea desconocido? Con ello, muestra que el autor no es un punto de origen de la comunicación -no hay tal cosa-, sino un rol relacionado con otros roles y prácticas interpretativas, jurídicas, etc. Entre las posibles formulaciones y desarrollos de esta problemática he escogido la de "autoridad", en el sentido de "saber socialmente reconocido" (D'Ors, 1979: 111-121), de "fuerza de la inteligencia» o "fuerza de las ideas» (Beltrán, 2013); se habla entonces de «autoridad espiritual» como opuesta a la «temporal» (Frye, 1970), o simplemente de autoridad frente al poder o la potestad; también cabe hablar de "legitimidad" (Lyotard, 1979; Agamben, 2013). A poco que se elabore, se verá que la autoridad está ligada a otras nociones como las de confianza y verdad. Creo que salta a la vista que esta es una faceta de la cultura y la comunicación enormemente conflictiva en nuestros días, desde el nivel más superficial -la multiplicación de la difusión de enunciados por medios digitales,

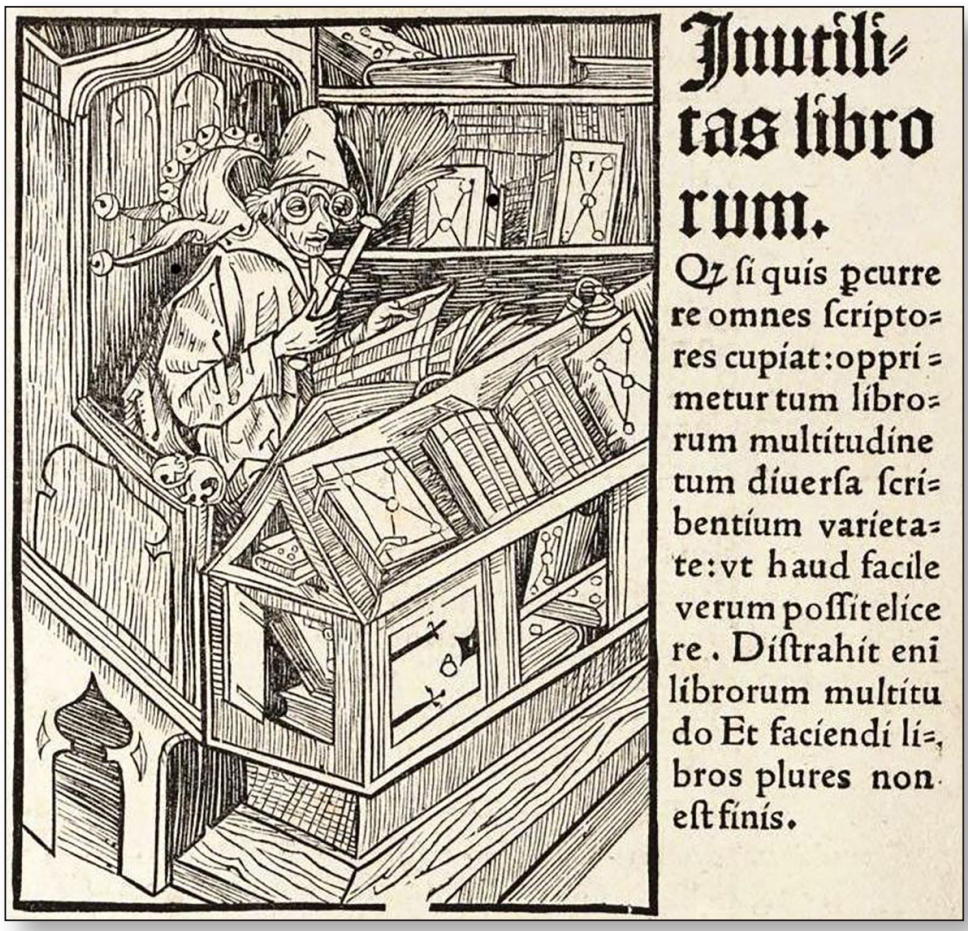

Fig. 1. Grabado del fol. XI de la «Stultifera navis» de Sebastian Brant, Basilea 1498. que atraen la atención pero no despiertan confianza; la política de la posverdad, antes llamada mentira y manipulación- hasta el nivel más básico: la civilización occidental ha universalizado la participación en el poder político que llamamos democracia -o al menos ha proclamado el ideal de su universalización-, y ha universalizado la participación en el saber mediante la enseñanza ${ }^{1}$, pero no ha resuelto la armonización o engranaje entre ambos, no ha fundado el poder en el saber, por lo que padecemos un exceso de poderío con un déficit de legitimidad (Guardini, 1986; Putnam, 1992: 180-200) [fig. 1].

1. La universalización por medios digitales (Lyotard, 1979: 83-82) es una paparrucha, como ya hizo ver Platón a propósito de la escritura: no es saber, sino apariencia de saber y altanería (Fedro). 
Para tratar estas cuestiones en las breves páginas de este ensayo y con cierto conocimiento de causa no tengo más remedio que adoptar una cierta restricción del enfoque. Entendiendo la cultura como un vasto sistema de prácticas comunicativas en sentido amplio, prestaré atención a las prácticas lingüísticas, especialmente a las llamadas literarias, con el convencimiento de que mis observaciones serán aplicables, mutatis mutandis, a otras áreas de interés de esta revista. ${ }^{2}$

Tal como la concibo, la Teoría de la Literatura consiste en abordar el estudio de la comunicación y el lenguaje humanos, y de los propios humanos que se comunican, por el extremo más complicado y sofisticado. En tal sentido, es el extremo opuesto a la filosofía analítica. Un filósofo analítico pretende explicar el lenguaje cavilando sobre enunciados como «El lucero de la mañana es el lucero de la tarde», «El actual rey de Francia es calvo», o «El gato está sobre la alfombra». Un teórico de la literatura, en cambio, empieza por enunciados como la Ilíada, la Divina comedia, el Quijote, Fausto, o En busca del tiempo perdido y todo lo que se ha podido hablar y escribir sobre ellos, en todas sus dimensiones sociales e históricas. ${ }^{3}$ Creo que estos ejemplos muestran que la cuestión de la autoridad no es ajena a la Teoría de la Literatura; entre otros rasgos que diferencian "El gato está sobre la alfombra» y el Quijote es que el segundo tiene algo que puede llamarse autoridad. ${ }^{4}$ Ahora bien, la Teoría no debe dar por supuesto que hay tal cosa como la literatura y la autoridad que esta tenga o haya tenido, sino más bien convertirlas en problema: ¿cómo es que ha llegado a haber literatura, y cómo es que la literatura ha alcanzado autoridad, y de qué tipo?

Lo que quisiera proponer en este ensayo es que para dar una respuesta satisfactoria hay que recurrir a algunos conceptos que han tenido una amplia tradición en un campo vecino, pero no idéntico, a los estudios literarios: el campo de los estudios bíblicos. El texto de la Biblia tal como lo conocemos hoy se ha elaborado a lo largo de siglos, y ha sido objeto de escrutinio minucioso durante más tiempo aún. La Biblia y los textos literarios han sido objeto de prácticas comparables, si es que no han sido las mismas. Algunos conceptos bíblicos se han trasvasado a la literatura de manera explícita; otros, de forma menos evidente. Son tres los conceptos que quiero examinar, para considerar su conexión bíblica y su pertinencia para la literatura y la cultura contemporáneas. Se trata de tres modelos de autoridad en el uso de la palabra: la profecía, la interpretación y la ficción. Los dos primeros son más o menos antitéticos: el discurso del profeta tiene una autoridad propia, mientras que el intérprete deriva su autoridad del texto interpretado. Esta contraposición es familiar para los estudios bíblicos al menos desde que el Evangelio explica cómo percibía la gente la enseñanza de

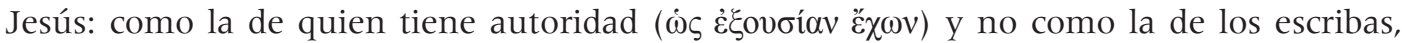
oi $\gamma \rho \alpha \mu \mu \alpha \tau \tilde{i} \varsigma$, maestros de letras que explican los textos de otros (Marcos 1: 22). El tercer concepto, ficción, es un poco excéntrico en este entorno, pero espero mostrar su carácter transversal para la Biblia y la literatura. Paso ya a comentarlos por orden. ${ }^{5}$

2. Para una primera aproximación a estas cuestiones en relación con la emblemática, ver Galván, 2011.

3. Si resulta chocante llamar por igual «enunciado» al objeto de la filosofía analítica y de la teoría literaria, recuérdese que Aristóteles escribió que el enunciado ( $\lambda$ óyos) puede ser uno o unitario, bien por significar una cosa sola, como la definición del ser humano, o bien por conjunción; y el ejemplo de esto último es la Ilíada (Poética 1457a28-30).

4. También se puede llamar «aura» (Benjamin, 1991; Beltrán, 2017).

5. Además de la bibliografía que iré citando ad locum, son relevantes los libros de Northrop Frye (1982, 1990) sobre la Biblia, la literatura y la autoridad/poder; ver también Galván 2008 y 2009 para una síntesis de algunas facetas de la cuestión.

IMAGO, NÚM. II, 2019, 67-83 


\section{PROFECÍA}

La profecía es una noción relativamente concreta, sobre todo si nos ceñimos a la Biblia y a los llamados "profetas escritores», pero es elusiva para la mentalidad contemporánea. ¿Qué son estos profetas? Max Weber los consideró «demagogos políticos» caracterizados por hablar abiertamente al público, es decir, por dirigirse a la opinión pública (1921: 282); Ortega y Gasset dice que fueron «los primeros intelectuales hebreos» (1965: 145), contemporáneos -si no anteriores- de los intelectuales griegos, los filósofos. Distingue Ortega entre el profeta como intelectual y el profeta como adivino extático, tal cual lo describen los antropólogos en sociedades antiguas y no tan antiguas. A su juicio, el intelectual, llámese profeta o filósofo, se caracteriza por estar en contra. ¿En contra de qué? Por un lado, de la opinión común, y por eso, en cierto sentido, en contra de su propio pueblo. Aquí se enreda Ortega en una disquisición filológica sobre la transmisión y traducción de Amós 7: 15, que no importa mucho. También se le podría objetar que su caracterización de la profecía es limitada, porque no tiene en cuenta otro ingrediente, como es la consolación del pueblo; ${ }^{6}$ pero es que -dice él- no pretende describir todo el fenómeno del profetismo, sino captarlo in statu nascendi, en la idea de que ese momento revela su verdadera naturaleza. Por otro lado, el profeta está en contra del poder político; pero no desde una posición de partido (Weber, 1921: 289), sino desde una posición personal, individual. Y desde su individualidad aporta un principio de racionalidad: ver claro lo que las cosas son y el sentido que tiene la historia. Esto lo llama Ortega «poder espiritual» y «legitimidad». Ya se sabe cómo trataba el poder político a los representantes del poder espiritual. (Para completar este panorama, habría que elaborar también la diferencia que mantiene el profetismo no solamente con respecto al poder político sino también con respecto a la autoridad sacerdotal; pero quizá esta línea no es tan relevante para la situación contemporánea.)

Aquí surge una cuestión de gran interés, analizada por la investigación bíblica. El individuo profeta, aislado y marginado, pudo convertirse sin embargo en foco de una comunidad profética. Sus dichos se conservaron, se organizaron y elaboraron. Aunque se los ha llamado "profetas escritores», en general no fueron ellos quienes compusieron los libros que llevan sus nombres. ${ }^{7}$ Qué es esto de atribuir a un individuo particular un libro, de poner al individuo como garante de la autoridad de la palabra? Esto es diferente de las atribuciones, pseudoepigráficas o no, del Pentateuco a Moisés, el salterio a David y el Qohélet a Salomón, etc. En estos casos parece que el personaje, por sus hechos y su poderío, tiene un prestigio propio, que deriva hacia los escritos; en el caso de los profetas, no tienen más prestigio que el de ser profetas. Y luego, ¿cómo se transmite la autoridad desde un escrito hacia otros? La posibilidad de esa transmisión es la razón por la que tenemos un deutero-Isaías y un trito-Isaías, etc.

No hace falta detallar que la autoridad que se arroga el profeta tiene un fundamento y se reconoce por unos criterios. El fundamento es la elección del profeta por Dios, que figura al comienzo de algunos libros (Isaías 6:1-8; Jeremías 1:4-5; Ezequiel 1:1-3); y los criterios son: la concordancia de su mensaje con la Torá (Jeremías 23:21-22); el cumplimiento de sus predicciones (Deuteronomio 18:22); y -lo más interesante- incluso antes de que se cumpla una

6. Como señala Weber (1921: 286), el profeta no se complace ni triunfa cuando se cumple su predicción -esto lo diferencia de un analista o tertuliano contemporáneo-, sino que pasa inmediatamente a promover la esperanza en tiempos mejores por la misericordia de Dios.

7. Ver, por ejemplo, Jeremias, 1996, y Troxel, 2012. El libro de Wyrick (2004) no da exactamente lo que anuncia su título, pero también es interesante. 
predicción, se garantiza su autenticidad profética porque predice una desgracia (Jeremías 28:8-9). Esto es, queda claro que el profeta no habla para halagar a sus oyentes, sino que dice lo que estos no quisieran oír. Pues bien: ¿qué papel tienen ahora en la comunicación las nociones de fundamento y de criterio, sean estos u otros? [fig. 2].

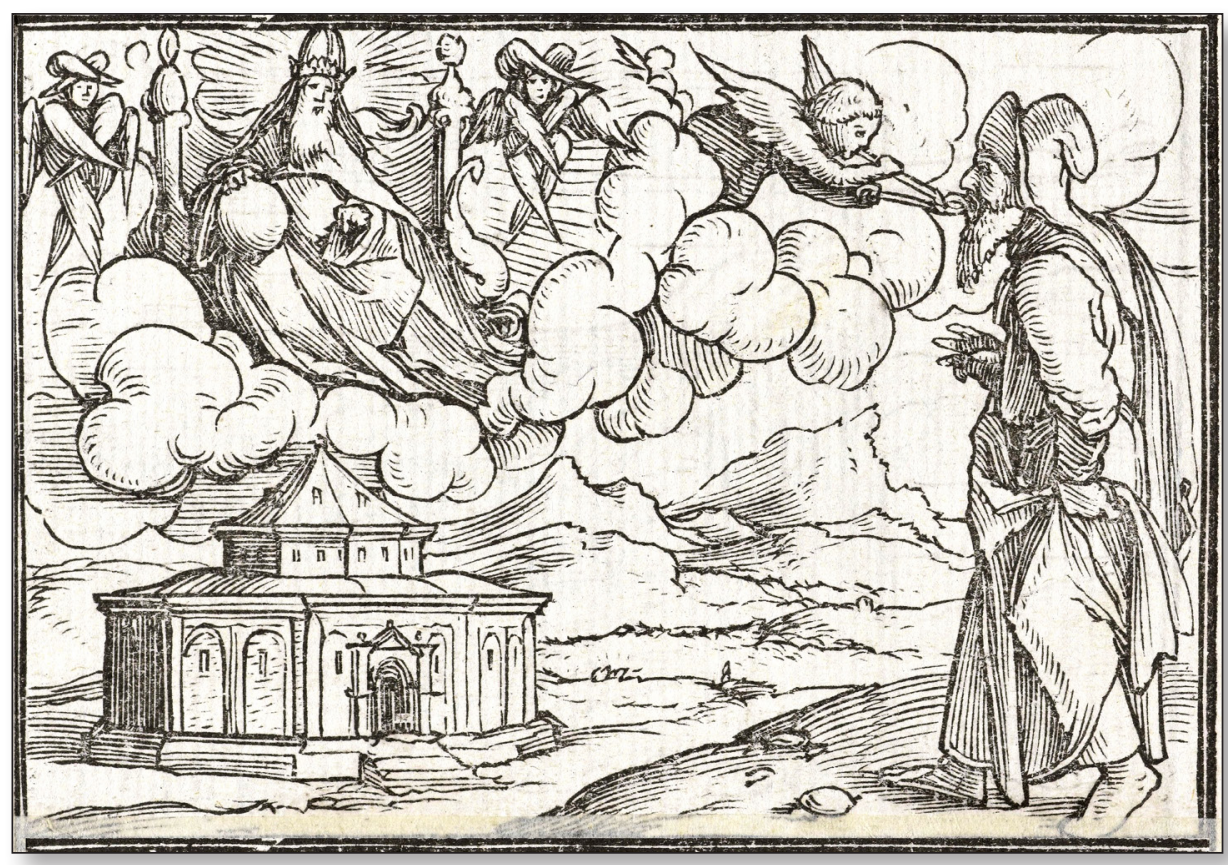

Fig. 2. Visión de Isaías, Holbein, Imágenes del Antiguo Testamento.

La problemática es muy vasta, y voy a limitarme a unas acotaciones, que no pueden ser completas, pero pretendo que sean significativas. Simplificando, puede decirse que la figura del profeta, como distinta del poder político y de la jerarquía religiosa, viene a menos. Sería interesante estudiar sus reactivaciones, como en el caso peliagudo de Savonarola, pero no es este el lugar. Ahora bien, si ese tipo de autoridad es una pieza necesaria en la sociedad, ¿dónde se la encuentra, cuando no hay profetas? La respuesta de John Milton es que su función puede cumplirla la libre discusión en el espacio público, particularmente gracias a la libertad de imprenta, que él intentó en vano defender con su Areopagitica en 1644. Milton sostiene que la censura previa es funesta, porque socava la autoridad de la enseñanza, al poner al maestro bajo tutela; y además tiende a aceptar solo lo que corresponde a la opinión común, mientras que las ideas más arriesgadas, aunque bien pueden venir dictadas por el Espíritu de Dios, encuentran el paso cerrado (Milton, 1999: 28-29). Vale la pena notar que este argumento ha vuelto a emplearse en la actualidad para oponerse a la revisión por pares en las publicaciones académicas (Bal, 2018). Volviendo a Areopagitica: la libre circulación y discusión del pensamiento permitirá, dice, que se cumpla el deseo de Moisés de que no solamente los setenta ancianos, sino todo el pueblo se convierta en profetas (Milton 1999: 42; ver Números 11:29). El discurso de Milton es admirable, pero algo debe de fallar en él, porque no parece ser esto lo que hemos conseguido ahora que se ha generalizado el acceso a los medios de difusión digitales. 
Veamos ahora una evolución quiástica en la concepción del profetismo. A finales de la Edad Media y durante la primera parte de la Moderna, se explica la figura del poeta como un continuador o imitador de los profetas, mientras que en el siglo XIX encontramos, al revés, que se caracteriza al profeta como un tipo de poeta. Por ejemplo, Giovanni Boccaccio justifica que los poetas usen alegorías y fray Luis de León que usen versos porque alegorías y versos se encuentran ya en los profetas y por tanto tienen el respaldo de la autoridad divina. Otro aspecto de esta concepción del poeta es que pone el acento sobre su individualidad en la elaboración verbal de sus textos, pero no sobre su contenido. En la España del siglo XVI Fernando de Herrera escribe que el mérito del poeta está en ser «cuidadoso del ornamento y composición de la lengua, sin procurar los sentimientos remotos del común juicio de los hombres»; e incluso "cuanto es más común, siendo tratado con novedad, tanto es de mayor espíritu, y, si se puede decir, más divino» (Herrera, 2001: 564); y en la Inglaterra del XVIII Alexander Pope mantiene que el ingenio poético ofrece:

What oft was thought, but ne'er so well express'd;

Something, whose truth convinc'd at sight we find,

That gives us back the image of our mind. (vv. 296-300)

Es decir, el fundamento de la autoridad del poeta es el sentir común de la gente, y el criterio para reconocerla es que uno comprueba en sí mismo la verdad de lo que se le dice, a la vez que advierte lo novedoso y acertado de la forma. ${ }^{8}$

Según avanza la Edad Moderna, la exaltación de la creatividad poética -que había empezado en el Renacimiento, cuando aparece ya la equiparación del poeta con Dios ${ }^{9-}$ lleva a concebir los poetas no como voceros del sentir común, sino como individuos singulares que revelan una verdad, sea sobre el mundo o sobre el lenguaje. Percy B. Shelley ( $A$ Defence of Poetry, 1821/1844) caracteriza al poeta como legislador y profeta a la vez, porque contempla el presente tal cual es, descubre las leyes que deberían ordenarlo, y también avizora el futuro, de tal manera que sus pensamientos son las semillas de lo que florecerá y dará fruto en tiempos posteriores (Shelley, 1994: 482-83), y concluye aplicando al poeta un concepto de la teología aristotélica:

Poets are the hierophants of an unapprehended inspiration; the mirrors of the gigantic shadows which futurity casts upon the present; the words which express what they understand not; the trumpets which sing to battle, and feel not what they inspire; the influence which is moved not, but moves. Poets are the unacknowledged legislators of the world. (508; cursiva mía)

El poeta es, según Shelley, no solamente creador, sino también motor inmóvil. Para semejante autoridad se dan diferentes fundamentos y criterios, que sería muy largo detallar.

8. La idea se encuentra ya en la antigüedad clásica, como reconoce Pope desde la primera edición, al remitir en nota al pie a Quintiliano; en efecto, este había escrito: "Naturam intueamur, hanc sequamur. Omnis eloquentia circa opera vitae est, ad se refert quisque quae audit, et id facillime accipiunt animi, quod agnoscunt» (Quintiliano, Inst. Orat. VIII.iii.71; ver Pope, 1711: 19).

9. El tema es muy vasto y no puede tratarse aquí con el detalle que merece; ver Weinberg, 1961, y Kappl, 2006. Ya en el siglo XVI se paragona el poeta con Dios; por ejemplo, se atribuye a Tasso el haber dicho "che il Poeta era cosa divina, e i Greci il chiamano con un attributo, che si dà a Dio, quasi volendo inferire, che nel mondo non ci è chi meriti nome di creatore, che Dio e il Poeta" (Serassi, 1785: 492-493; la frase fue citada, no con exactitud, por Shelley). También López Pinciano escribe: «la poética hace la cosa y la cría de nuevo en el mundo, y por tanto le dieron el nombre griego que en castellano quiere decir 'hacedora', como poeta 'hacedor', nombre que a Dios solamente dieron los antiguos" (1596: 167). 
Baste mencionar la idea de genio, considerado como voz de la naturaleza o del espíritu de un pueblo o nación; y la divisa de "épater le bourgeois», la casi obligación de escandalizar. ${ }^{10}$ Sin embargo, quisiera detenerme un poco en ciertas consideraciones de Unamuno y de Ortega y Gasset, que ponen el fundamento del profetismo en la individualidad extrema. Unamuno, en un artículo menor, pero significativo, conecta los tres temas que he seleccionado para este ensayo. ${ }^{11}$ El profeta -escribe- es quien mejor interpreta el futuro porque "revela lo oculto en las honduras presentes»; o por mejor decir lo crea: "predice y augura y anticipa y adivina; no porque diga lo que ha de ocurrir sino porque ocurre lo que él dice. [...] El que crea un mito crea una fuente de realidades futuras" (Unamuno, 1958: 511).

En cuanto a Ortega, se aplica a sí mismo la expresión «clamar en el desierto», y glosa:

Esta, señores es la misión del intelectual que lo es de verdad, del profeta, grande o chico: clamar en el desierto [...]. Porque la misión del intelectual es ser el hombre que desde su desierto, es decir, desde su radical soledad -y el hombre solo es en su verdad, solo es en sí mismo cuando es en su soledad-clama e invita a los demás para que ingrese cada cual en su propia soledad. [...] Cuando el hombre se queda solo, de verdad solo, ipso facto aparece Dios. De modo que es quedarse solo con Dios. (1965: 226-227)

El final es atípico, sin duda, pero revelador de que la cuestión del fundamento de la autoridad permanecía abierta hasta el final de la Modernidad.

¿Qué hay de esto en la situación actual? ¿Qué profetismo admite la cultura postmoderna? Quizá puedan darse tantas respuestas como caracterizaciones hay de la Postmodernidad. Yo voy a contentarme con tres trazos.

En primer lugar, pienso que el contraste global más claro entre la Modernidad y la Postmodernidad consiste en el cambio de actitud hacia el futuro. La Modernidad confía en el progreso y la emancipación; la Postmodernidad está a la expectativa de un desastre acarreado por la misma ciencia y técnica de la que antes se esperaban todos los bienes. Primero fue la catástrofe nuclear, ahora es el cambio climático. Pues bien, si un criterio de autenticidad profética era el anunciar desgracias, ¿quién necesita actualmente que se las anuncien? Otro rasgo del profetismo consistía en el ejercicio de una autoridad individual frente a figuras instituidas como la monarquía y el sumo sacerdocio; pero es que actualmente tanto los poderes políticos como los religiosos advierten de la expectativa del desastre. Y, sin embargo, parece que seguimos teniendo necesidad, quizá psicológica, de profetas individuales. Valga como muestra la atención que atrae Greta Thunberg.

En segundo lugar, en la Postmodernidad se va desvaneciendo la diferencia entre la alta y la baja cultura, la producción cultural restringida para unos pocos conocedores y la producción para las masas. Hasta hace unas décadas, el carácter minoritario de una obra de arte o de literatura era un indicio, si no una prueba, de su calidad. Actualmente se aducen los números millonarios de ventas como indicio de calidad. Este desarrollo tiene algunos aspectos positivos, pero está claro que afecta a una de las características esenciales del profetismo: oponerse a la dóxa, a la opinión generalizada. En cierta manera se produce un regreso a la situación altomoderna, cuando el poeta era un vocero del sentir común. Tanto más cuanto hoy parece imposible cumplir el requisito romántico de escandalizar.

10. Ver un panorama en Praz, 1942, por ejemplo.

11. El artículo se titula «Yo, individuo, poeta, profeta y mito», y apareció originalmente en la revista Plus Ultra de Buenos Aires en agosto de 1922. 
En tercer lugar, se ha extendido cierta desconfianza o escepticismo respecto de la individualidad originante; y no sin razón. Para Jacques Derrida, el funcionamiento del lenguaje tiene como condición de posibilidad la ausencia del hablante; para Roland Barthes, el escritor deja de ser la fuente y el garante del sentido de los textos para convertirse en un simple lugar donde se entrecruzan los códigos, la intertextualidad; para Michel Foucault, la autoría es una hipóstasis de ciertos procedimientos de la crítica, cuando no una noción ideológica que tiene el efecto contrario al que se proclama: no el de multiplicar los discursos y el sentido gracias a la creatividad, sino el de restringirlos. Estas posturas quizá se han expresado de manera chocante, pero están muy lejos de ser mera sofística.

Por supuesto, hay una faceta paradójica en esto: parece que las obras de arte son repetición de lo ya dicho, pero la crítica y la interpretación sí despliegan la creatividad y se oponen a la dóxa. Así se encuentra, de manera programática, en la propuesta de la Teoría Crítica de «leer contra la veta»; también en los proyectos de descubrir una dimensión profética en la cultura popular, como hace Mikhail Bakhtin -y me pregunto hasta qué punto se puede aplicar esta idea a la Biblia, que, como escribió alguien, "[it] would still be a popular book if it were not a sacred one» (Frye, 1957: 116)-. Esto lleva al siguiente apartado, el de la interpretación.

\section{INTERPRETACIÓN}

"Avec la littérature ou la philosophie, le discours religieux [...] est sans doute le domaine où les techniques de commentaire sont les plus anciennes, les plus abondantes et les plus sophistiquées" (Maingueneau, 2009: 6). Esto se verifica ya en el texto mismo de la Biblia. Primero, es una peculiaridad del profetismo bíblico, si se compara, por ejemplo, con los oráculos grecolatinos, que no se contenta con un simbolismo oscuro o un mensaje ambiguo, sino que suele incluir su interpretación y aplicación (Weber, 1921: 303-307). ${ }^{12}$ Esto plantea la cuestión de la autoridad de la interpretación. En los profetas, a veces está resuelta porque se atribuye la interpretación al mismo fundamento que la visión o el símbolo, es decir, a la palabra de Dios, como en las visiones de Amós 7-8, la canción de la viña de Isaías 5, la alegoría de las águilas y la vid de Ezequiel 17. Pero además, la exégesis intrabíblica toma muchas otras formas: aclaraciones interpoladas, reinterpretaciones, revisiones, combinaciones, etc. (Fishbane, 1985). Por tanto, se puede distinguir, en principio al menos, entre el enunciador original y el intérprete o comentador.

Esta distinción da lugar a las paradojas del comentario: paradoja de la repetición y la novedad, y de la autoridad ajena y la propia. Por un lado, la práctica del comentario permite construir nuevos discursos, pero bajo la condición de limitarse a decir-explicitar, aclarar- lo que ya estaba dicho, de alguna manera, en el texto original, atribuyendo a este una riqueza de sentidos múltiples y escondidos (Foucault, 1971). Por otro lado, si el comentario revitaliza el texto, también socava su autoridad, porque implica una insuficiencia, una necesidad de actualización que solamente puede llevarse a cabo con la actividad del intérprete (Fishbane, 1985: 15). Es más, la práctica de la interpretación socava confianza en toda comunicación: una hermenéutica laxa, decía Schleiermacher (1977: 92), presupone que la comprensión se produce espontáneamente y solo hay que evitar los malentendidos ocasionales; la hermenéutica estricta presupone que lo natural es el malentendido, y la comprensión debe buscarse deliberadamente en cada punto.

12. Con excepciones notables, claro está, como los cantos del Siervo de Yavé en Isaías. 
He mencionado la exégesis intrabíblica, una forma de comentario que está siendo bien estudiada y que merece mayor atención por parte de todos los que nos interesamos por la comunicación. En cierto sentido, representa una pervivencia de la oralidad en una incipiente cultura escrita. Cuando alguien habla, es capaz de reformular y matizar sus afirmaciones para facilitar la comprensión y quizá llegar a un acuerdo con sus oyentes. En cambio, la escritura en sentido estricto es una mera apariencia de comunicación: un discurso escrito parece hablar, como si tuviera inteligencia, pero si uno le pregunta algo para aprender, se limita a responder siempre lo mismo (Platón, Fedro 275d). Pues bien, las reelaboraciones del texto son una suerte de reformulaciones orales, y es un fenómeno que requiere atención en la comunicación contemporánea, que tiene muchos componentes de oralidad, no principalmente por la difusión de archivos multimedia que ha venido después de la radio y la televisión, ${ }^{13}$ sino especialmente por los medios escritos que ofrecen la posibilidad de conocer las reacciones de los lectores y responder a ellas. Las ventajas son indudables, pero también los costes. Hay una cierta apariencia o aparato de presencia del emisor que puede generar confianza; pero el proceso de la comunicación es alterable y quizá deja de ser recuperable la forma original de las fases pasadas: sin necesidad de una organización maquiavélica como el Ministerio de la Verdad de 1984, la información en una cultura oral es más contingente e inestable. ${ }^{14}$

Tenemos, por otro lado, la diferenciación entre un texto fijado y el comentario que se añade a él. Este fenómeno también se documenta en la Biblia (Nehemías 8), distinguiéndose entre la lectura del libro de la ley y su explicación para facilitar la comprensión. En este caso el comentario es oral, pero pronto pasa a la escritura, y sabemos que hay un desarrollo, quizá al principio paralelo y después sin duda convergente entre la exégesis judía y la enarratio poetarum que formaba parte de la tradición gramatical grecolatina, como resulta explícito, por ejemplo, en la sistematización que presenta Agustín de Hipona en De doctrina christiana $^{15}$ [fig. 3]. Con esto se establece una diferencia entre los discursos fundamentales -discursos con "aura», como dije al principio-, que son objeto de comentario, y los discursos secundarios o de gestión, entre los cuales están los que comentan los primeros (Maingueneau \& Cossutta, 1995;

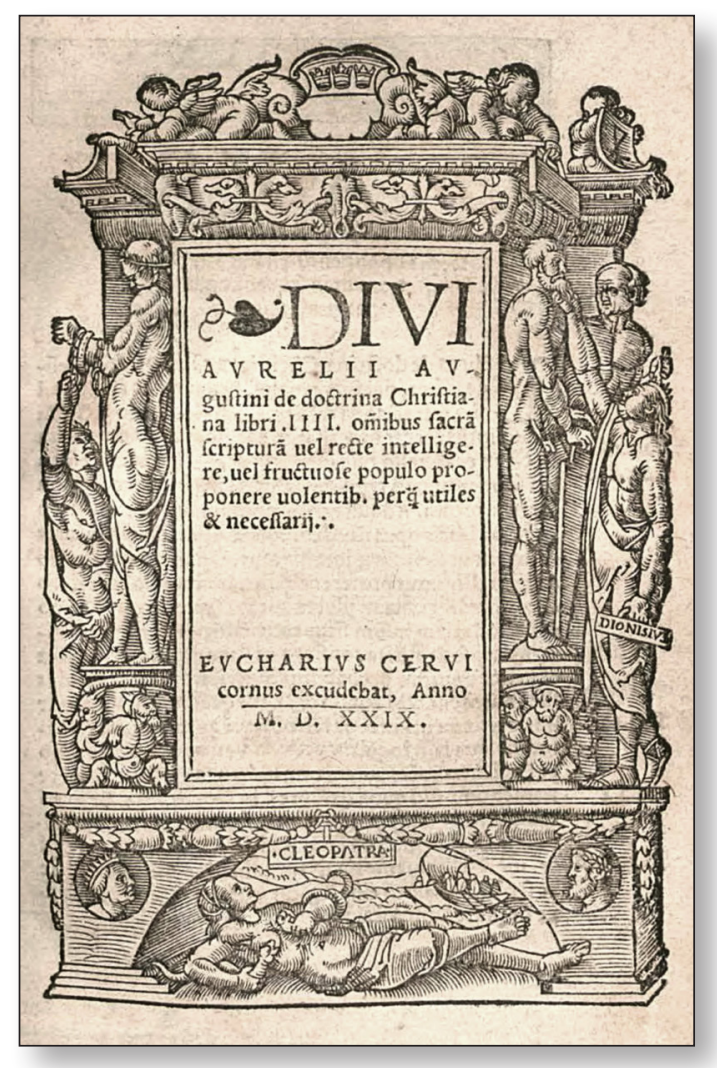

Fig. 3. Portada del De Doctrina Christiana de san Agustín, Colonia, Hittorpius, 1529.

13. Quizá ya no hay que hablar de "oralidad segunda», como hacía Ong (1982).

14. Goody \& Watt (1963) hablan del tratamiento "homeostático" de la tradición en las sociedades orales; se con-

serva lo que es relevante para la situación actual; lo demás se olvida, o se reinterpreta, se transforma, etc.

15. Ver el panorama que ofrecen Pépin, 1976; Irvine, 1994. 
Maingueneau, 1999). Tal es la estructura de dos campos discursivos distintos, pero comparables: el religioso y el literario. ${ }^{16}$

Esta estructura da lugar a dos problemas de autoridad o legitimación: el del campo discursivo como tal y el de cada comentador particular. Respecto de lo primero, hay que fijarse en la diferencia entre lo que los discursos de gestión dicen y lo que hacen. En el caso de la literatura es bastante claro que los discursos de gestión dicen que la autoridad emana de los textos fundamentales - «grandes libros»-, y que dicha autoridad justifica el interés de interpretarlos; pero lo que hacen es producir, mantener y administrar esa aura de autoridad al dar por supuestos su existencia y su valor como premisa y justificación de sí mismos.

Una analogía adicional entre el campo religioso y el literario se encuentra en su relación con el campo global de la comunicación y la cultura contemporáneas. Hasta una fecha que no puedo precisar, la presuposición del valor y la importancia de los discursos fundamentales -la Biblia y, digamos, la Eneida o el Quijote- podía darse por buena para una comunidad histórica y social amplia, bien fuera nacional o supranacional. Sin embargo, en la actualidad esa presuposición falla. La autoridad de los discursos fundamentales del campo no es reconocida socialmente. Parece clara la diferencia entre estudiar el Quijote cuando era visto como pieza fundamental para contestar «la magna pregunta: Dios mío, ¿qué es España?» (Ortega, 1914: 129) y estudiar el Quijote como fetiche de una tribu de eruditos. En este caso, los discursos de gestión no pueden derivar para sí ninguna legitimidad de los discursos fundamentales -aunque lo sigan pretendiendo- simplemente porque estos no la tienen.

Queda entonces la cuestión de la autoridad propia del comentarista. Hay que distinguir entre su autoridad interna al campo -qué credenciales necesita alguien para ser exégeta de la Biblia o intérprete del Quijote, cuestión que no trato aquí- y su autoridad externa, orientada a la comunicación en la sociedad. Si está cerrado el camino de justificarla por el texto comentado, habrá que justificarla por la aportación propia del comentario. Creo que también en este aspecto los estudios bíblicos llevan la delantera, en la medida en que han elaborado la idea que expresó así Agustín de Hipona: «Ego vero evangelio non crederem, nisi me catholicae Ecclesiae commoveret auctoritas» (Contra epist. Fund., cap. 5; PL 42, 176). En cambio, los estudios literarios no han entrado en pacífica posesión del concepto de «COmunidades interpretativas» que hace años propuso Stanley Fish (1980), sino que más bien lo han tomado como objeto de hostigamiento y burla.

Otra faceta de la cuestión es cuáles son los criterios de un comentario exitoso, de una interpretación correcta. Hay dos nociones que aparecen sin cesar. Una es el mantra «dejar hablar a los textos», dar el sentido inherente al texto. Pero "sentido del texto» es una expresión engañosamente simplificadora. El sentido es una función con una constante -el texto- y varias variables: circunstancias, códigos y convenciones que se empleen, etc. (Schmidt 1983: 244; Barwise 1989: 59-77). Lo que sucede es que a veces damos por supuesto que determinadas circunstancias, códigos y convenciones son de rigor; pero en realidad esto habría que argumentarlo en cada caso. La otra noción recurrente es la de «intención del autor». Precisamente, esta sirve para determinar unas circunstancias, etc.: las del autor. Pero también sobre las dificultades de esta vía nos pueden ilustrar los estudios bíblicos: tenemos, por ejemplo, la intención de quienquiera que compuso un canto del Siervo de Yavé; luego, ¿fue intención suya, o de otro, atribuirlo al profeta Isaías? ¿Y de quién fue la intención de incluirlo en el libro de Isaías? (que no es necesariamente lo mismo que lo anterior). Más la

16. La bibliografía sobre la literatura como "campo» o subsistema social es muy amplia; ver al menos Schmidt, 1989 y 1991; Bourdieu, 1992; Maingueneau, 2004. 
intención comunicativa de incluir este libro en el canon; y las modificaciones del canon, que modifican el contexto y las relaciones interdiscursivas del canto, del libro, del conjunto de libros, etc. Esta es una problemática que Gadamer planteó a todas las ciencias históricas con el concepto de «historia de los efectos»; el estudio de la literatura intentó afrontarla con la estética de la recepción, y últimamente se está abordando con la metodología del análisis del discurso, con nociones como las de «discurso repetido» y «aforización». Los estudios bíblicos pueden aportar luz sobre estas cuestiones y por tanto facilitar una mejor comprensión de la extraordinaria recirculación y recontextualización de discursos que se da en la sociedad contemporánea. Evidentemente, la cuestión de la canonicidad, que he mencionado de paso, también deberíamos estudiarla de la mano de los estudios bíblicos (ver Kermode, 1979).

Otra faceta del problema de la intención del autor es: ¿cómo podemos conocerla? La respuesta que ya dio Agustín de Hipona es: no podemos (Confesiones XII.xXIII-XXXI, 32-42; PL 32, 838-844) ${ }^{17}$ Lo que podemos hacer es una reconstrucción racional del acto comunicativo, o de la sucesión de actos que he mencionado, asumiendo que el emisor realiza su enunciado conforme a unas expectativas y disposiciones que es razonable atribuir a los destinatarios, y que podemos conocer de forma más o menos independiente. Esto implica que la reconstrucción o interpretación tendrá que ser revisable si aparecen datos nuevos o si descubrimos la pertinencia de datos que antes no habíamos tenido en cuenta. Es decir, tendrá carácter tentativo o hipotético, que es, en cierto sentido, lo contrario de la autoridad. Y esto me lleva a la tercera y última parte de esta charla, el tema de la ficción, que voy a exponer de forma más sintética.

\section{FICCIÓN}

La ficción es omnipresente en la vida cotidiana, por no hablar de la vida pública y política, y representa una parte enorme del negocio del entretenimiento, con las novelas, el cine, las series y los videojuegos. Sin embargo, o quizá por ello mismo, el concepto de ficción es uno de los más elusivos. En la filosofía del lenguaje se suele elaborar en relación con el de verdad -como lo contrario de la verdad o como no pertinencia de la oposición verdad/falsedad-, o con el de seriedad -mediante el contraste seriedad/juego- pero lo que quiero proponer hoy es entenderlo más bien en relación de contraste con la autoridad. ${ }^{18}$

Pienso que el prototipo que tenemos de ficción son las obras que llamamos literarias -y posiblemente también el cine-; y como algunas de esas obras existen desde la Antigüedad remota, podemos creer que siempre ha habido ficciones. Pero esto encubre el hecho de que durante muchos siglos ha faltado un vocabulario para hablar concretamente de ficción; y, en su ausencia, no está claro que existiera el concepto. En griego se hablaba de «cosas no

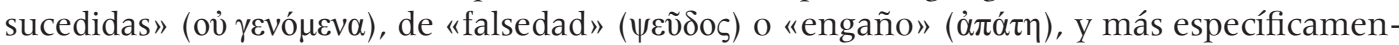
te de «cosas fabricadas» $(\pi \lambda \alpha \dot{\sigma} \sigma \mu \alpha \tau \alpha)$, que coincide con el sentido de la expresión latina fictio.

17. Ya Platón había puesto en boca de Sócrates la afirmación de que no podemos demostrar nuestras afirmaciones acerca de la intención del poeta (Protágoras 347e); ver Galván, en prensa.

18. Entre las investigaciones sobre el concepto de ficción quiero remitir aquí a Routley, 1979; Schmidt, 1980; Currie, 1990; Walton, 1990; Woods, John y Peter Alward, 2004; Lamarque, 2014; García-Carpintero, 2016. En todas ellas falta la dimensión histórica que subrayo en estos párrafos y que pretendo elaborar más en trabajos futuros (entre ellos «From poièsis to fiction», en preparación para un volumen que aparecerá en Edition Reichenberger). 
En el latín humanístico, la noción de fictio se especializa dentro de la práctica de la interpretación alegórica de la mitología clásica: la fictio o fabula es una corteza que hay que quitar o atravesar para llegar al grano o fruto de la verdad. Este uso y sentido se traslada enseguida a las lenguas modernas. En esa época, se extiende a significar cualquier argumento inventado, sea alegórico o no. Y de este modo la "ficción" sigue considerándose un tipo de falsedad o incluso de mentira, como se ve a cada paso, por ejemplo, en la Filosofía antigua poética (1596) de Alonso López Pinciano.

En estas circunstancias, ha habido resistencias al empleo del concepto de lo ficcional en la interpretación de la Biblia, por sus implicaciones morales. Agustín de Hipona admite al menos una distinción: "Non enim omne quod fingimus mendacium est: sed quando id fingimus quod nihil significat, tunc est mendacium. Cum autem fictio nostra refertur ad aliquam significationem, non est mendacium, sed aliqua figura veritatis» (Quaest. Ev. II.51; PL 35, 1362). Esta es una concepción semántica de la ficción, pues la explica usando conceptos de referencia y verdad. ${ }^{19}$

Otro aspecto sale a relucir en el contraste de lo que comentan Maimónides y Tomás de Aquino a propósito del libro de Job. Maimónides apoya la opinión de quienes mantienen que Job no existió y el libro es una parábola, pero afirma que, existiese o no, su caso es una fuente de perplejidad para todos (Guía para perplejos, III.xxii). En cambio, Tomás de Aquino, en el proemio de su Expositio super Job, escribe:

Fuerunt autem aliqui quibus visum est quod iste Iob non fuerit aliquid in rerum natura, sed quod fuerit quaedam parabola conficta ut esset quoddam thema ad providentiae disputationem, sicut frequenter homines confingunt aliqua facta ad disputandum de eis. Et quamvis ad intentionem libri non multum differat utrum sic vel aliter fuerit, refert tamen quantum ad ipsam veritatem.

Precisamente, la actual definición pragmática y retórica de la ficción consiste en que la existencia o inexistencia del personaje y los hechos -la referencia y la verdad en términos semánticos- sean irrelevantes para el sentido de un discurso. Parece que santo Tomás, admitiendo esto, se resiste a calificar de ficcional un libro entero de la Biblia: la verdad semántico-referencial le parece demasiado importante ${ }^{20}$ [figs. 4 y 5].

En las citas de Agustín de Hipopna y de Tomás de Aquino vemos una orientación hacia la intención comunicativa del escritor, mientras que Maimónides considera la reacción de los lectores. Estas dos posibilidades se encuentran ya en Orígenes, que es el último autor que voy a comentar. En Contra Celsum enfoca la intención autorial: lo que pretende establecer es que ciertos relatos de la Biblia son deliberadamente alegóricos al igual que lo son ciertos mitos griegos. Los escritores bíblicos tienen el mismo derecho que Hesíodo y Platón a emplear la

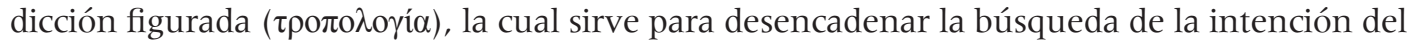
autor (IV.39). En cambio, en De principiis habla de las ficciones -lo no sucedido y también lo

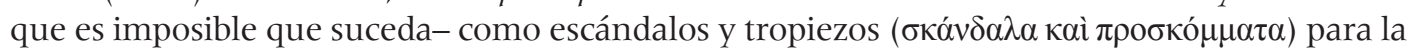

19. Con la autoridad de Agustín de Hipona, el planteamiento tiene una larga perduración. Cita estas líneas, por ejemplo, Martín Martínez de Cantalapiedra en el primero de sus Libri decem hypotyposeon theologicarum, sive regularum ad intelligendum scripturas divinas (Salamanca, 1582). Por otra parte, aunque la idea de Agustín parece clara, su formulación quizá genera más problemas que resuelve ( "no significar nada», "referirse a una significación», etc.). Puede verse una síntesis de ciertas dificultades del planteamiento semántico en Galván \& Vela, 2019; y en Galván, 2017a y 2017b, algunas propuestas para evitar los problemas de la referencialidad sin salir de la semántica lógica.

20. Las pruebas que aduce un poco más adelante (y que omito por brevedad) constituyen una petición de principio. 
comprensión, que impiden que el sentido literal sea puramente seductor y estimulan a aprender algo más digno de Dios (IV.ii.9):21 mientras, que, por otra parte, admite que a veces no se alcanza a ver claro el sentido de las figuras, bien por falta de preparación o de tiempo, o bien porque, incluso contando con preparación y tiempo, la interpretación es exageradamente di-

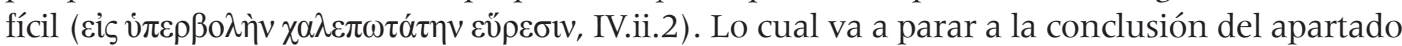
anterior: la interpretación de la ficción no puede ser más que tentativa y revisable.

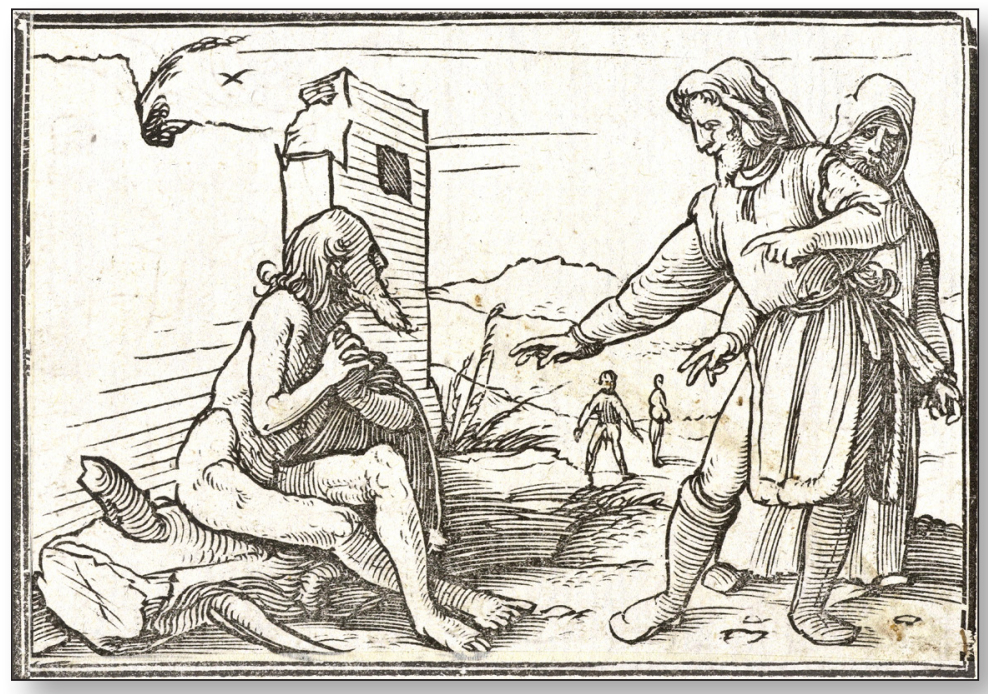

Fig. 4. Ilustración del libro de Job xv, Holbein, Imágenes del Antiguo Testamento.

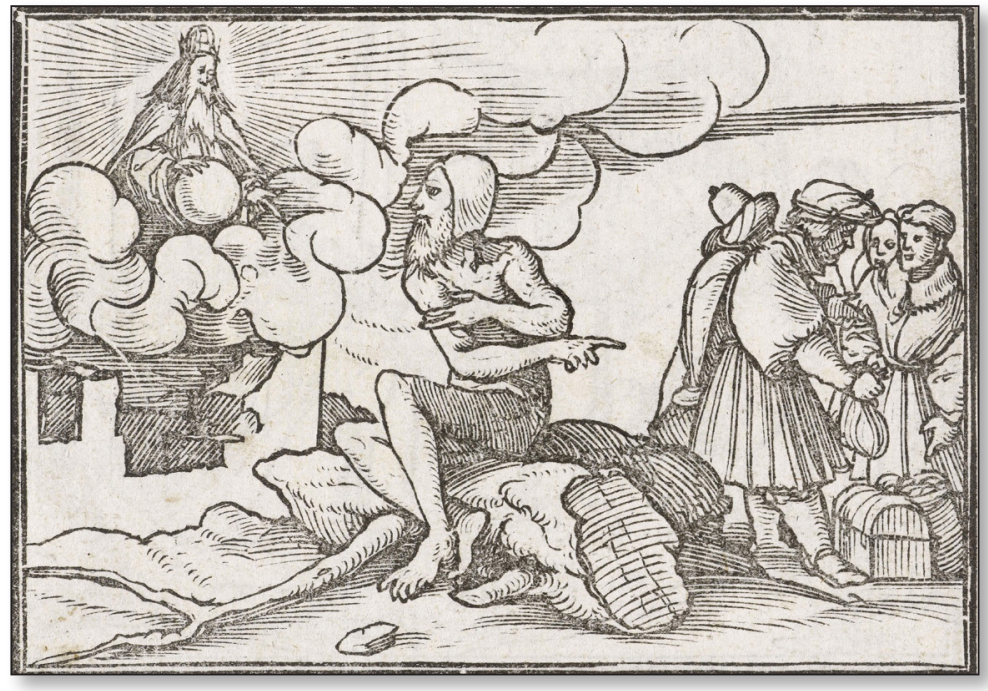

Vig. 5. Ilustración del libro de Job xxxIII, Holbein, Imágenes del Antiguo Testamento.

21. Sobre la problemática del escándalo para la comunicación, ver Gelz, Hüser \& Ruß-Sattar, 2014; para el estudio de un caso, ver Galván, 2015.

IMAGO, NÚM. II, 20I9, 67-83 
Esta idea de ficción coincide con otro conjunto de expresiones acerca de ella que se en-

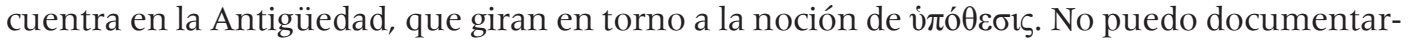
lo aquí, pero consiste, en suma, en presentar un enunciado no como afirmación o negación que puede ser verdadera o falsa, sino como premisa que se puede examinar para ver qué consecuencias se derivan de ella, considerando la probabilidad y coherencia internas de la

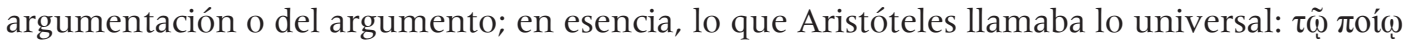

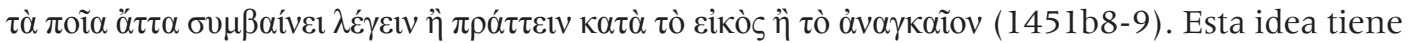
mayor elaboración en la tradición retórica, donde Quintiliano habla de argumentum a fictione o hipotético (Instit. Orat. V.x.95), y Hermógenes de Tarso de la prueba "fabricada" (

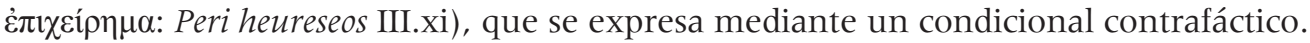

$\mathrm{Y}$, sin negar que esto tiene una relación con la verdad, quería subrayar, como dije, el aspecto de autoridad. En la primera sección, cuando hablaba del profetismo, se trataba de la autoridad del hablante -su pretensión de enunciar una verdad-. En la segunda, de la tensión entre la autoridad del texto comentado y la del intérprete. Ahora se trata de la renuncia a la autoridad; al menos, de renunciar a ella como condición de partida o razón suficiente para que se acepte lo dicho, con la esperanza de recuperarla al final con el rostro más amable de la confianza y la convicción. La ficción no pretende enunciar una determinada verdad; la ficción, como se ha dicho del símbolo (Ricoeur, 1959), "da que pensar». Toca al oyente o lector acoger ese discurso, considerarlo como una posible forma de vida, desarrollarlo y aplicarlo para descubrir si puede ser, y cómo, «intrínsecamente convincente» (Bakhtin, 1981: 342-349).

\section{FINAL}

El panorama que he recorrido es demasiado vasto y complejo para permitir unas breves conclusiones, pero hay que terminar. Me limitaré a subrayar tres ideas. La primera es que el diálogo interdisciplinar con los estudios bíblicos puede ser muy fecundo: en esa tradición se han tratado durante décadas o siglos fenómenos que, mutatis mutandis, están muy vivos en la actualidad. La segunda es que la Teoría de la literatura en particular y la comprensión de la cultura en general no puede dar nada por supuesto, ni siquiera que hay tal cosa como literatura y cultura; al contrario, tiene que examinar cómo se han constituido estas a lo largo de la historia, mediante qué ideas, con qué prácticas y qué modelos. La tercera y última es que, posiblemente, la autoridad se ha ido para no volver, y esto, que es conspicuo en la ficción y por ello mismo permite su disfrute, también puede ser beneficioso en los demás ámbitos que he repasado. Comencé diciendo que estaba pendiente el conjugar la universalización del poder con la universalización del saber, y esto no puede hacerse sin responsabilidad: responsabilidad en el poder y responsabilidad en el saber, dar y examinar razones, en vez de empeñarse en tener razón. 


\section{BIBLIOGRAFÍA}

Agamben, G. [2013]. El misterio del mal: Benedicto XVI y el fin de los tiempos, Buenos Aires, Adriana Hidalgo.

Bakhtin, M.M. [1981]. The Dialogic Imagination, ed. M. Holquist, Austin, University of Texas Press.

BAL, M. [2018]. "Let's Abolish the Peer-Review System», Media Theory, 3 de septiembre de 2018 (http://mediatheoryjournal.org/mieke-bal-lets-abolish-the-peer-review-system/). Visitado el 15 de mayo de 2019.

BARwiSE, J. [1989]. The Situation in Logic, Stanford, CSLI.

Beltrán, L. [2013]. "Apuntes para una genealogía del poder», en J.L. Rodríguez García \& L. Beltrán Almería (coords.), Cultura o barbarie, Zaragoza, Mira Editores, 33-52.

Beltrán Almería, Luis (2017): Genvs: genealogía de la imaginación literaria. De la tradición a la Modernidad. Barcelona: Calambur.

Benjamin [1991]. "Das Kunstwerk im Zeitalter seiner technischen Reproduzierbarkeit» (orig. 1939), en Gesammelte Schriften, ed. R. Tiedemann \& H. Schweppenhäuser, Frankfurt a.M., Suhrkamp, vol. I.2, 471-508.

Bourdieu, P. [1992]. Les Règles de l'art: Genèse et structure du champ littéraire, Paris, Seuil.

Currie, G. [1990]. The Nature of Fiction, Cambridge, Cambridge UP.

D'Ors, A. [1979]. Ensayos de teoría política, Pamplona, Eunsa.

FISH, S. [1980]. Is There a Text in This Class? The Authority of Interpretive Communities. Cambridge (MA), Harvard UP.

Fishbane, M.A. [1985]. Biblical Interpretation in Ancient Israel, Oxford, Clarendon Press.

Foucault, M. [1971]. L'Ordre du discours, Paris, Gallimard.

Foucault [1994]. "Qu'est-ce qu'un auteur" (orig. 1969), en Dits et écrits, Paris, Gallimard, vol. I, pp. 789-821

Frye, N. [1957]. Anatomy of Criticism: Four Essays, Princeton, Princeton UP.

Frye, N. [1970]. "The Problem of Spiritual Authority in the Nineteenth Century», en The Stubborn Structure: Essays on Criticism and Society, Ithaca (NY), Cornell UP, 241-256.

Frye, N. [1982]. The Great Code: The Bible and Literature, New York, Harcourt Brace Jovanovich.

FrYe, N. [1990]. Words with Power: Being a Second Study of The Bible and Literature, New York, Harcourt Brace Jovanovich.

Galván, L. [2008]. "Estrategias retóricas de autoridad», en V. Balaguer \& J.L. Caballero (eds.), Palabra de Dios, Sagrada Escritura, Iglesia, Pamplona, Eunsa, 249-262.

GALVÁn, L. [2009]. "Educación, propaganda, resistencia: Literatura y poder en teorías, tópicos y controversias de los siglos XVI y XVII», en I. Arellano, C. Strosetzki, E. Williamson (eds.), Autoridad y poder en el Siglo de Oro, Pamplona, Eunsa / Madrid, Iberoamericana / Frankfurt a. M., Vervuert. 51-87.

Galván, L. [2011]. «Cuestiones de autoría y autoridad en libros de emblemas y otras colecciones didácticas», Imago: revista de emblemática y cultura visual, 3, 85-92.

GALVÁn, L. [2015]. «Sociedad y literatura: escándalo y fascinación del tema del suicidio en el siglo XIX», en L. Beltrán y otros (eds.), En el balcón de la Modernidad: las culturas ante la tradición, lo popular y lo culto, Barcelona, Calambur, 125-51.

Galván, L. [2017a]. "La lógica bidimensional y la interpretación de textos de ficción», Revista de Literatura, 79/158, 365-390. 
GaLVÁN, L. [2017b]. "Counterfactual claims about fictional characters: philosophical and literary perspectives», Journal of Literary Semantics, 46. 2, 87-107.

Galván, L. [en prensa]. "Aforización, discurso repetido y literatura», en L. Galván 8 R. Zafra (eds.), Dominique Maingueneau: enunciados extraordinarios, Pamplona, Eunsa.

GaLVÁn, L. \& Vela Valldecabres, D. [2019]. «Ficción y universos de discurso», en R. González Ruiz, I. Olza \& Ó. Loureda Lamas, Lengua, cultura, discurso: estudios ofrecidos al profesor Manuel Casado Velarde, Pamplona, Eunsa, 973-988.

García-CARPIntero, M. [2016]. Relatar lo ocurrido como invención: una introducción a la filosofía de la ficción contemporánea, Madrid, Cátedra.

Gelz, A., HüSER, D. \& Russ-SATTAR, S., eds. [2014]. Skandale zwischen Moderne und Postmoderne. Interdisziplinäre Perspektiven auf Formen gesellschaftlicher Transgression. Berlin, De Gruyter.

Goody, J. \& WATT, I. [1963]. "The Consequences of Literacy», Comparative Studies in Society and History, 5.3, 304-345.

Guardini, R. [1986]. Das Ende der Neuzeit. Die Macht (orig. 1950, 1951), Ostfildern, Matthias Grünewald / Paderborn, Ferdinand Schöningh.

Herrera, F. [2001]. Anotaciones a la poesía de Garcilaso (orig. 1580), Madrid, Cátedra.

Holbein, Hans [2001]. Imágenes del antiguo testamento, ed. de Antonio Bernat Vistarini, Palma de Mallorca, Olañeta-UIB, 2001.

Irvine, M. [1994]. The Making of Textual Culture: "Grammatica» and Literary Theory, 350-1100, Cambridge, Cambridge UP.

Jeremias, J. [1996]. Hosea und Amos: Studien zu den Anfängen des Dodekapropheton, Tübingen, Mohr.

KapPL, B. [2006]. Die Poetik des Aristoteles in der Dichtungstheorie des Cinquecento, Berlin/New York, De Gruyter.

Kermode, F. [1979]. "Institutional Control of Interpretation», Salmagundi, 43, 72-86.

LAmarque, P. [2014]. The Opacity of Narrative, London / New York, Rowman \& Littlefield.

López Pinciano, A. [1596]. Philosophía antigua poética, Madrid, Thomas Iuncti.

LyotaRd, J.-F. [1979]. La Condition postmoderne. Paris, Minuit.

Maingueneau, D. [1999]. "Analysing Self-Constituting Discourses», Discourse Studies, 1.2, 175-199.

Maingueneau, D. [2004]. Le Discours littéraire: Paratopie et scène d'énonciation, Paris, Armand Colin.

Maingueneau, D. [2009]. "Introduction. La difficile émergence d'une analyse du discours religieux", Langage et société, 130, 5-13.

Maingueneau, D. \& Cossutta, F. [1995]. "L'analyse des discours constituants», Langages, 29/117, 112-125.

Milton, J. [1999]. Areopagitica, and Other Political Writings, Indianapolis, Liberty Fund.

ONG, W.J. [1982]. Orality and Literacy: The Technologizing of the Word. London: Methuen \& Co.

Orígenes [1913]. De principiis, ed. P. Koetschau, Leipzig, J.C. Hinrich.

Ortega y Gasset, J. [1914]. Meditaciones del Quijote, Madrid, Publicaciones de la Residencia de Estudiantes una síntesis.

Ortega y Gasset, J. [1965]. Obras completas, vol. IX, 2. ${ }^{a}$ ed., Madrid, Revista de Occidente.

PÉPIN, J. [1976]. Mythe et allégorie: les origines grecques et les contestations judéo-chrétiennes, Paris: Études Augustiniennes.

Pope, A. [1711]. An Essay on criticism, London, Printed for W. Lewis.

Praz, M. [1942]. La carne, la morte e il diavolo nella letteratura romántica, 2. a ed. aum., Torino, Einaudi. 
Putnam, H. [1992]. Renewing Philosophy, Cambridge (MA), Harvard UP.

Ricoeur, P. [1959]. "Le symbole donne à penser», Esprit, nueva serie, 7/8, 60-76.

Routley, R. [1979]. "The Semantical Structure of Fictional Discourse», Poetics, 8, 3-30.

SERASSI, P. [1785]. La vita di Torquato Tasso, Roma, Pagliarini.

SchleIERMACher, F.D.E. [1977]. Hermeneutik und Kritik, orig. 1838, ed. M., Frank, Frankfurt a. M., Suhrkamp.

SснміDт, S. J. [1980]. «Fictionality in literary and non-literary discourse», Poetics, 9, 525-546.

Schmid, S.J. [1983]. "Interpretation: Sacred Cow or Necessity?», Poetics, 12, 239-258.

Schmid, S.J. [1989]. Die Selbstorganisation des Sozialsystems Literatur im 18. Jahrhundert, Frankfut a.M., Suhrkamp.

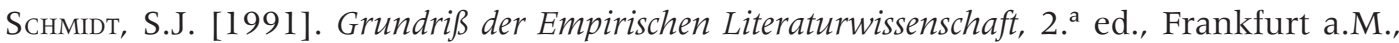
Suhrkamp.

Shelley, P.B. [1994]. Shelley's Poetry and Prose: Authoritative Texts, Criticism, ed. D. H. Reiman \& S.B. Powers, New York, Norton \& Company.

Tomás de Aquino [s.a.]. Expositio super Iob ad litteram, en http://www.corpusthomisticum.org (consultado el 16 de octubre de 2019)

Troxel, R.L., [2012]. Prophetic Literature: From Oracles to Books, Malden (MA), Wiley-Blackwell.

Unamuno, M. de [1958]. Obras completas, vol. 10, ed. M. García Blanco, Madrid, Afrodisio Aguado.

Walton, K. [1990]. Mimesis as Make-Believe, Cambridge (MA), Harvard UP.

Weber, M. [1921]. Gesammelte Aufsätze zur Religionssoziologie, III: Das antike Judentum, Tübingen, J.C.B. Mohr (Paul Siebeck).

Weinberg, B. [1961]. A History of Literary Criticism in the Italian Renaissance, 2 vols., Chicago, University of Chicago Press.

Woods, J. \& Alward, P. [2004]. "The Logic of Fiction», en D. M. Gabbay y F. Guenthner (eds.), Handbook of Philosophical Logic, $2^{a}$ ed., Dordrecht, Kluwer, vol. XI, 241-316.

WyricK, J. [2004]. The Ascension of Authorship: Attribution and Canon Formation in Jewish, Hellenistic, and Christian Traditions, Cambridge (MA), Harvard UP. 
